\title{
Enhancing the Productivity of Niger Delta Shale Formation through Matrix Stimulation: An Experimental Study
}

\author{
Anthony Kerunwa, Ndubuisi U. Okereke, Ifeanyi Tasiewojiewhor \\ Federal University of Technology, Owerri, Nigeria \\ Email: anthonykerunwa@rocketmail.com
}

How to cite this paper: Kerunwa, A., Okereke, N.U. and Tasiewojiewhor, I. (2020) Enhancing the Productivity of Niger Delta Shale Formation through Matrix Stimulation: An Experimental Study. Open Journal of Yangtze Gas and Oil, 5, 117-130. https://doi.org/10.4236/ojogas.2020.53010

Received: April 28, 2020

Accepted: June 6, 2020

Published: June 9, 2020

Copyright $\odot 2020$ by author(s) and Scientific Research Publishing Inc. This work is licensed under the Creative Commons Attribution International License (CC BY 4.0).

http://creativecommons.org/licenses/by/4.0/ (c) (i) Open Access

\begin{abstract}
Shales have very low permeabilities often within the range of nanodarcies and as such production from shales have been complex and challenging because of poor conductive network. In this work, experiments were conducted to ascertain the effect of matrix acidizing on oil recovery of shale formation in the Niger Delta. Four core samples, S1, S2, S3 and S4 gotten from the Niger Delta shale formation were used. Experiments carried out focused on gas flooding using nitrogen gas at pressures of 1300 psia, 1800 psia and 2300 psia before acid treatment and acidizing with HCL as the choiced acid at different concentrations. XRD was used to analyze the mineral content of the core samples and the analyzed result shows that the predominant mineral constituents of the shale samples are calcite $(47 \%)$ and dolomite $(11 \%)$, which are $\mathrm{HCl}$ acid soluble constituents. At the end of the experiment, study revealed increase in oil production indicating enhanced productivity as a result of acid treatment and appropriate injection pressure of 800 psia. The result also revealed that the penetration rate in the range of $247.66 \mathrm{~min} /$ in to $139.95 \mathrm{~min} /$ in before acid treatment decreased to the range $21.67 \mathrm{~min} / \mathrm{in}$ to $6.61 \mathrm{~min} / \mathrm{in}$ after acid treatment.
\end{abstract}

\section{Keywords}

Acidizing, Recovery, Hydraulic Fracturing, Permeability

\section{Introduction}

Shale formations are now part of key oil and gas future sources in various parts of the worlds. Shales are rocks with permeability in nano-darcy and with mineralogies that are diverse. Shales are exploited through the techniques of horizontal drilling together with hydraulic fracturing, but hydraulic fracturing of hori- 
zontal well of shale formations is carried out stage-wise with a single stage having up twenty [1] [2]. In addition to acid flush [2], there are basically two stimulation techniques applied [3] [4] as alternatives to hydraulic fracturing: acid fracturing and matrix acidizing. Matrix acidizing is usually carried out at low pressures to eliminate fracturing the reservoir rock when acid is pumped into the well and permeability increased due to acid dissolution of sediment and mud solids. Permeability enhancement occurs by enlarging the natural pores of the reservoir with attendant stimulation of flow of hydrocarbons in immediate proximity to the wellbore. Acid fracturing involves pumping acid that is highly pressurized into the well, thereby causing a physical fracture of the reservoir rock resulting in permeability improvement through the dissolution of sediments. By this process, channels are formed through which flow of hydrocarbons may take place [2] [5]. Acidizing treatments are generally used to get rid of near wellbore damage and equally create artificial channels of flow in carbonate formations and sandstone; whereas limited treatments have been carried out on shale rocks [6] [7]. The most commonly used acid to stimulate production is hydrochloric $(\mathrm{HCl})$ and is useful in getting rid of impairments from reservoirs. Hydrochloric acid plus hydrofluoric acid (HF) [7] [8] may be used in the dissolution of silicate phases occurring in the reservoir rocks [7] [9]. The protection of the integrity of the well already completed requires that additives called inhibitors be introduced into the well to prevent the steel casing in the well from being broken down by the acid. Also, sequestering agent is added to block off the formation of precipitates of iron or gels which can clog the pores of the reservoir during an acid job, and a sequestering agent can be added [7]. Thus, effective acidizing is guided by practical limits in terms of volume and types of acid employed and [9] [10] [11] [12] and also the procedure utilized so as to achieve optimum formation damage removal around the wellbore [13] [14]. Although the acid system utilized in sandstone differs from that of carbonate but, the same practice is applied to both. In carbonate rock, wormholes are formed when hydrochloric acid enlarges the wellbore or tends to bypass the damage. Thus, there is an increase in permeability much more in carbonate than in the sandstone. Removal of large number of plugging in the carbonate or sandstone will consequently result in tremendous increase in the well productivity [15] [16]. Also, if formation is not damaged, poor or improper execution of acid treatment can reduce the existing natural formation permeability which will ultimately lead to reduced well productivity, especially in new well with low permeability [15] [16] [17]. Shale deposits present in Nigeria's Akata formation are in great volumes and they are volumetrically large enough to generate much oil and gas for Niger Delta province [18] [19]. There is great interest currently on the utilization of shale deposits as an energy source [20]. The utilization of the huge shale deposits offers great potential for increasing the production natural gas and crude oil for Nigeria, since $90 \%$ of Nigeria's export earnings is dependent on oil and gas [21]. To enhance the recovery of the oil in shale deposits requires two approaches which involves injection of gas: cyclic gas injection commonly known as 
huff-n-puff and constant gas injection which is otherwise known as gas flooding [22]. In this study, experiments were conducted to investigate the effect of acidizing on oil production of Niger Delta shale using core samples taken from the Niger delta shale formations. Gas flooding was therefore conducted on the core samples before and after acid treatment. This was necessary to ascertain the relative effect of acid treatment on the cores in relation to oil production and the average time of penetration into the cores at the time of breakthrough and compare with the results when no acid treatment was applied.

\section{Materials and Method}

\subsection{Materials}

The materials and equipment utilized in this study are shale core samples, Helium, Nitrogen cylinder filled with nitrogen gas, helium porosimeter, M9190 grace nanodarcy permeameter, computer tomography scanner, synthetic oil, brine, $\mathrm{HCl}$ acid, $\mathrm{NaCl}$, syringe pump, vaccum bell, XRD.

\subsection{Method}

\subsubsection{Shale Samples}

Four shale core samples S1, S2, S3 and S4 from four Niger Delta shaly sands within the Akata formation are utilized in this work. Each core sample has its distinct dimension. All the cores have a diameter of 1.5 inches each with lengths of 0.8 in., 1.2 in., 1.6 in., and 2.0 inches respectively. Helium porosimeter was used in the porosity measurement and the porosity varies from $10.18 \%$ to $13.64 \%$ and has an average value of $11.96 \%$. The permeability was also measured, averaged as 1.12 nanodarcies with M9190 grace nanoperm. Vacuum cell had the samples placed in it to vacuum the core samples

\subsubsection{Determination of Mineral Components of the Core Sample}

XRD technique was used in the determination of the mineral components of the shale samples. Several samples were crushed into powder. Each powdered sample was packed into the sample holder of the XR diffractometer and a test was conducted on the sample to identify the mineral components of the sample which involves scanning the sample with XR diffractometer with the door closed. After the identification of the mineral component of the sample, Rietveld Analysis was applied in the modeling of spectrum of XRD through the weight of reference spectra. In this experiment several samples were utilized to greatly reduce uncertainties. Figure 1 shows the XR diffractometer used for the mineral components determination

\subsubsection{Experimental Procedures}

1) The core samples were scanned using scanning computer tomography (CT-scan) to identify natural fractures.

2) Porosity measurement was done using Helium porosimeter at pressures of 80 psi, 110 psi, 140 psi and 170 psi. 


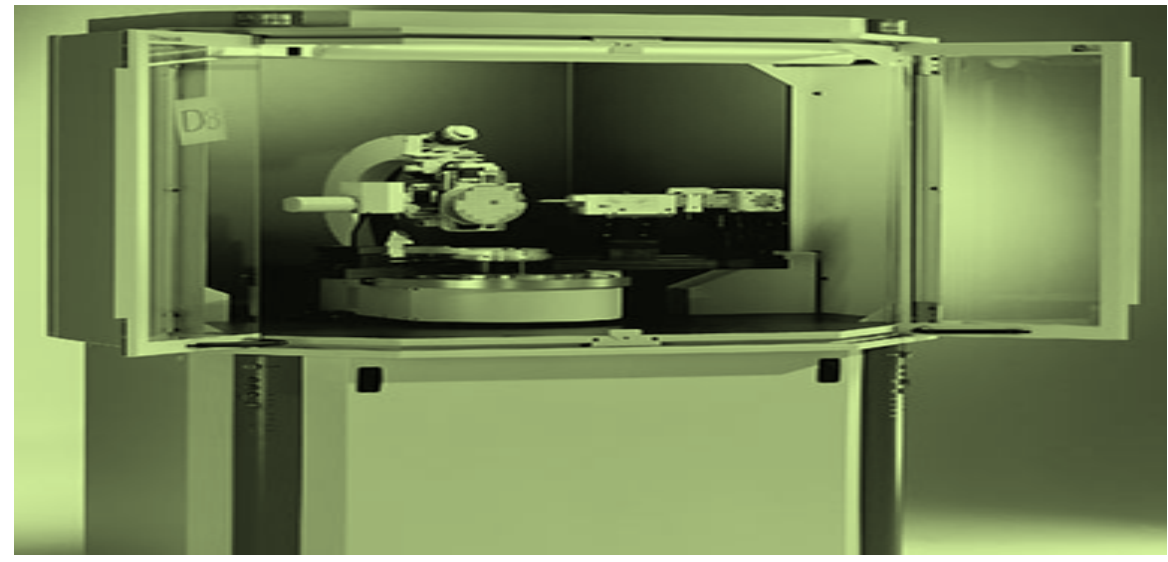

Figure 1. X-Ray (XR) Diffractometer.

3) Permeability was then measured with M9190 grace nanoperm

4) The core samples were placed in a vacuum bell to vacuum for 3 days

5) After the cores were vacuumed, the vacuumed core samples were placed in a saturator with enerpac pump connected to it. Synthetic oil was delivered into the saturator with the aid of the enerpac pump and the whole system raised to 2500 psi pressure for 3 days.

6) Gas flooding was applied in three stages at pressures: $1300 \mathrm{psi}, 1800 \mathrm{psi}$ and 2300 psi using $\mathrm{N}_{2}$ gas which was $99.9 \%$ pure and had a density of $0.001186 \mathrm{~g} / \mathrm{cc}$. For each of the stages, confining pressure of 800 psi greater than the flooding pressure was applied. This enabled the core sample to remain in place while the gas adequately penetrated the core sample. For each of the stages, time of penetration, time travel of the gas to specific core length and oil recovery results were measured and tabulated at the breakthrough time.

7) After the gas flooding, $\mathrm{HCL}$ was mixed with $\mathrm{NaCl}$ solution and this was done to prevent swelling of any clay during the acidizing experiment. The $\mathrm{HCl}$ was placed in four different concentrations of 5\%,10\%, 15\% and $20 \%$. The prepared solution of $\mathrm{HCl}+\mathrm{NaCL}$ was connected to the core holder through a delivery pipe. Each of the HCL concentrations was injected into the core samples through the syringe pump to get the samples acidized at a pressure of 1000 psi. The water was used to impose pressure on the piston that connects to the coreholder. After the treatment of acid, the core samples were further saturated with synthetic oil and gas flooding applied at 350 psi and then at 800 psi pressures to determine the impact of the core treatment with the acid. Figure 2 shows Gas flooding and acidizing schematic setup.

\section{Results and Discussion}

\subsection{Mineralogy Results of Core Sample}

The XRD results of the core samples taken from different shaly sands within the Akata formation are given in Table 1 and Figure 3. From the result the most prominent mineral constituents were calcite $(47 \%)$ and dolomite $(11 \%)$. The minerals are soluble in HCL and they constitute $58 \%$ of the total mineral composition. 


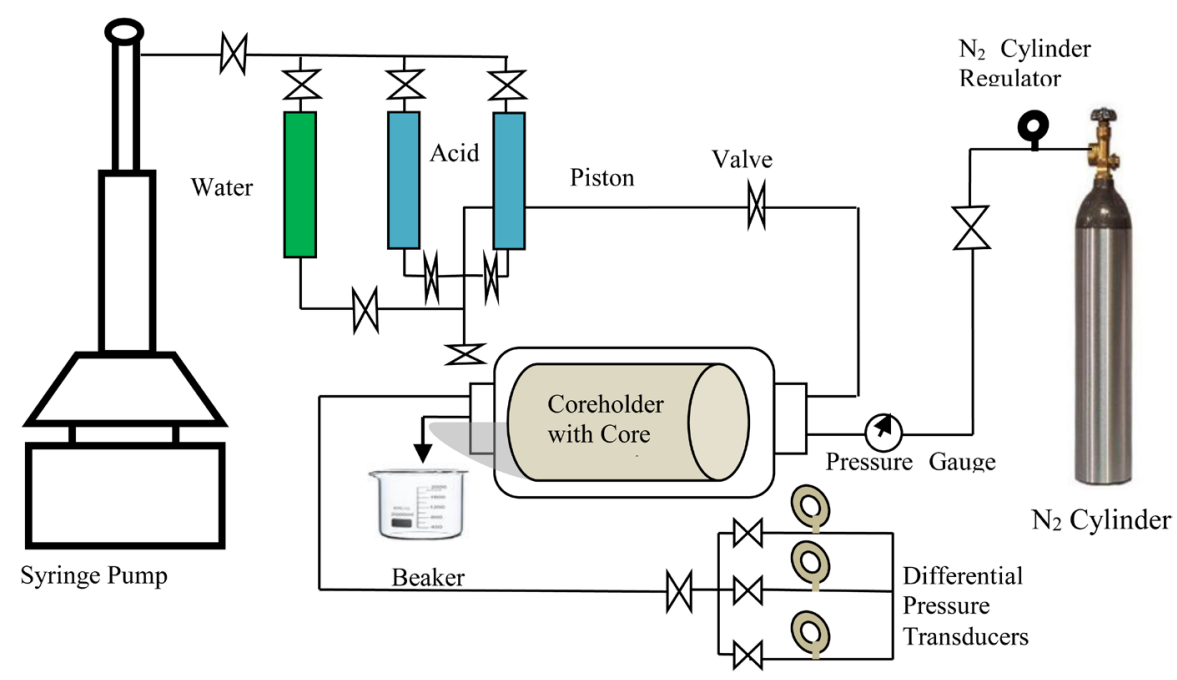

Figure 2. Gas flooding and acidizing schematic setup.

Table 1. XRD mineralogy results of the core samples from the Niger Delta.

\begin{tabular}{|c|c|c|c|c|c|c|}
\hline \multirow{2}{*}{$\mathrm{S} / \mathrm{N}$} & \multirow{2}{*}{ Constituents } & \multicolumn{5}{|c|}{ Concentrations } \\
\hline & & S1 & S2 & S3 & S4 & Average constituents \\
\hline 1 & Quartz & 8.2 & 4.1 & 4.5 & 3.2 & 5.0 \\
\hline 2 & Calcite & 37.4 & 42.5 & 55.2 & 52.1 & 46.8 \\
\hline 3 & Dolomite & 14.6 & 14.3 & 8.2 & 8.4 & 11.4 \\
\hline 4 & Illite & 10.2 & 4.9 & 3.8 & 4.2 & 5.8 \\
\hline 5 & Kaolinite & 4.4 & 2.2 & 2.6 & 1.8 & 2.8 \\
\hline 6 & Oglioclase Feldspar & 3.6 & 0.8 & 3.5 & 4.3 & 3.1 \\
\hline 7 & Albite & 1.2 & 1.1 & 1.8 & 1.4 & 1.4 \\
\hline 8 & Anhydrite & 2.7 & 19.1 & 4.2 & 2.5 & 7.1 \\
\hline 9 & Siderite & 12.4 & 4.8 & 12.8 & 15.3 & 11.3 \\
\hline 10 & Apatite & 5.3 & 6.2 & 3.4 & 6.8 & 5.4 \\
\hline & 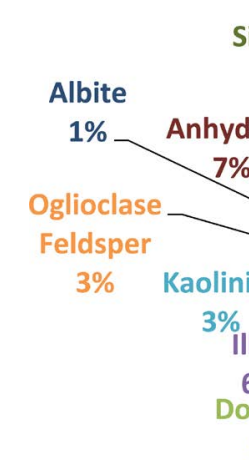 & & & & & $\begin{array}{c}\text { Calcite } \\
47 \%\end{array}$ \\
\hline
\end{tabular}

Figure 3. Average XRD mineral components of core samples.

Thus, the core samples are favourable to acidizing and holds great prospects for the acidizing treatment. Since there are no smectite which is chief constituent responsible for swelling, the very minimal amount of swelling which is expected 
to occur in the shale samples during the experiment will be prevented by the $\mathrm{NaCL}$ added to the $\mathrm{HCl}$. It is expected that post acidizing investigation would improve both the porosity and permeability of the formation.

\subsection{Oil Recovery}

Oil recovery is given as a function of injection pressure and as a function of acid concentration. Oil recovery as a function of the injection pressure before the acid treatment and after the acid treatment at the various flooded pressures of 1300 psia, 1800 psia and 2300 psia and the effect of acid treatment on the cores at 5\%, $10 \%, 15 \%$ and $20 \%$ HCL acid concentrations at pressure of 350 psia and 800 psia are reported below.

\subsubsection{Oil Recovery Factor at Different Injection Pressure before Acid Treatment}

From Figure 4, before acid treatment, the cores were flooded at pressures of 1300 psi, 1800 psi and 2300 psi. The results for these pressures show increasing values of oil recovery with increasing injection pressures for samples S2, S3 and S4. Generally, from the figure, sample S4 had the highest oil recovery of $17 \%$ which occurs at the injection pressure of 2300 psi. Sample S1 at an injection pressure of 1300 psi had $8 \%$ oil recovery, at higher injection pressure of 1800 psi contrary to what was obtained for samples S2, S3 and S4, had lower oil recovery of $5 \%$. When the injection pressure was increased to $2300 \mathrm{psi}$, the oil recovery was $7 \%$ lower than the $8 \%$ obtained at the injection pressure of 1300 . The oil recovery results of core S2, S3 and S4 signifies that pressure increases with oil recovery from the cores while sample S1 results show that after the injection pressure of 1300, some pores were isolated which did not participate in oil production but when the core was flooded at higher pressure, the isolated and dead-end pores were forced to participate in oil production as can be seen in Figure 4.

\subsubsection{Oil Recovery at Different Core Length}

From Figure 5, it can be seen that oil recovery increases with core length except for core S2 (1.2 in) with 7\% which was lower than that gotten in core S1 (0.8 in) with $8 \%$ recovery at injection pressure of 1300 psia. This shows that the initial permeability of core S2 is relatively smaller than those of others. Generally, higher injection pressures had higher recoveries for each of the core lengths

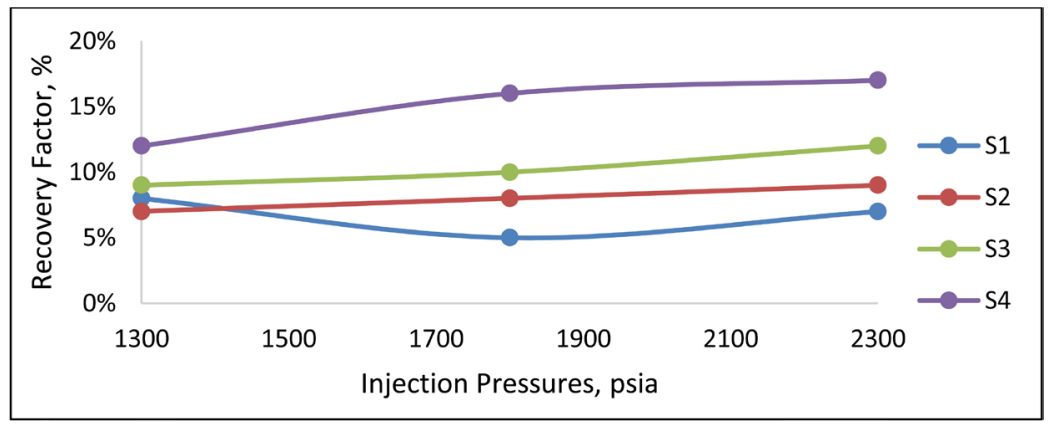

Figure 4. Oil recovery at different injection pressures before acid treatment. 
except for sample 1 which gave lower recovery at injection pressure of 1800 psia with isolated and dead-end pores which later became non-isolated at injection pressure of 2300 psia as explained in section 3.2.1. The low recoveries of S1 (0.8 in) was because S1 is very short leading to very short penetration rate and also shorter breakthrough time which did not allow for higher recovery

\subsubsection{Oil Recovery Factor after Acid Treatment at Different HCL Concentration}

Here, the result of oil recovery factor after the core has been treated with acid is presented below. Unlike the pre-acid treatment, the injection pressure was low and maintained at 350 psi for all the HCL concentrations used for the first case and then injection pressure of 800 psia for all the HCL concentrations used for the second case. The higher the length of the core, the higher the surface area to be contacted by the acid and the higher the hydrocarbon pore volume. From Figure 6, four different HCL concentrations were used at injection pressure of 350 psia. It can be observed from Figure 6 that oil recovery factor increases with increase in acid concentrations for all core samples used. At acid concentration of $20 \%$, oil recovery factor was very minimal in all the samples compared to what was obtained at $15 \%$ acid concentration. This shows that an optimal acid concentration is required; therefore increasing the concentration of HCL acid further means more operational cost on the oil produced. Thus if the oil produced due to the increment of the HCL concentration from $15 \%$ to $20 \%$ does not justify the economics of the incremental oil, it would be needless to increase the concentration of the acid.

From Figure 7, four different HCL concentrations were utilizes at injection

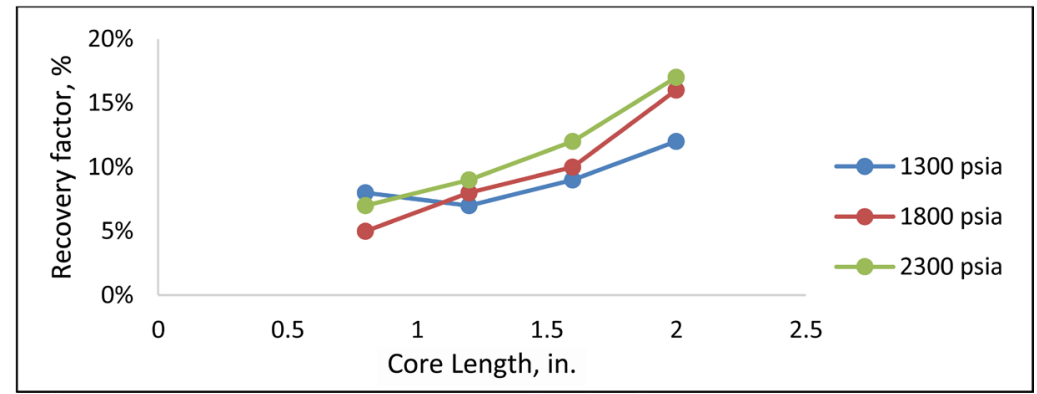

Figure 5. Oil recovery at different core length before acid treatment.

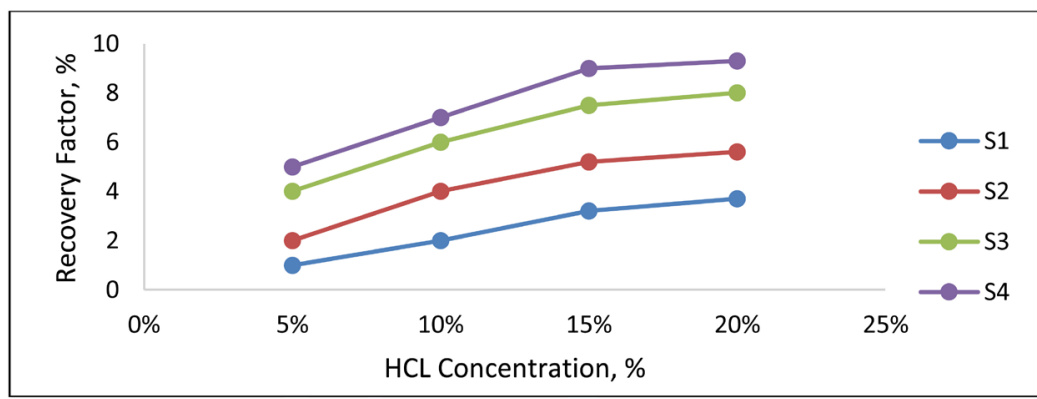

Figure 6. Oil recovery factor at different HCL concentration after acid treatment at 350 psia. 
pressure of 800 psia. It can be observed from Figure 7 that oil recovery factor increases with increase in acid concentrations also for all core samples used. At acid concentration of $20 \%$, oil recovery factor was very minimal in all the samples compared to what was obtained at $15 \%$ acid concentration. This again shows that optimal acid concentration is required; therefore increasing the concentration of HCL acid further means more operational cost on the oil produced as mentioned earlier. The oil recovery obtained at injection pressure of 800 psia after acid treatment was far higher than that obtained at the injection pressures of 1300 psia, 1800 psia and 2300 psia before acid treatment. This shows that acid treatment of the shaly matrix has enhanced productivity in the core samples utilized for this study and can be deployed to field scale applications. This is due to induced fractures which were developed after acid treatment, increase in porosity of the cores as a result of calcite being dissolved (Equation (1)) and improved permeability by the acid in the core samples.

$$
\mathrm{CaCO}_{3}+2 \mathrm{HCl} \rightarrow \mathrm{CaCl}_{2}+\mathrm{H}_{2} \mathrm{O}+\mathrm{CO}_{2}
$$

\subsection{Breakthrough Time (BT)}

\subsubsection{BT at Different Lengths of Core before Acid Treatment}

In this work, oil recoveries were measured at BT of the cores. From Figure 8, each core has its time of breakthrough at an applied injection pressure. Sample S1 had the shortest BT because of its short length while sample S4 which is the longest core, had the longest time of breakthrough. The highest time of breakthrough from the figure was 531 minutes and it occurred at 1300 psia injection pressure for sample S4 while the shortest BT was 10 minutes at 2300 psia for

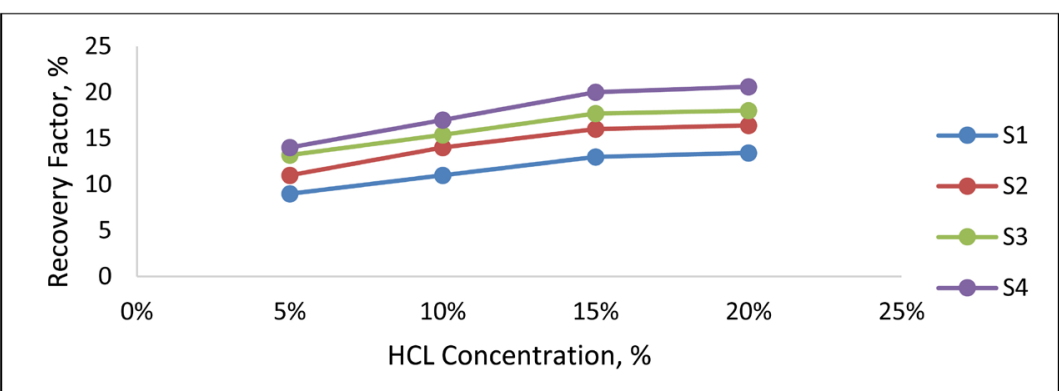

Figure 7. Oil recovery factor at different HCL concentration after acid treatment at 800 psia.

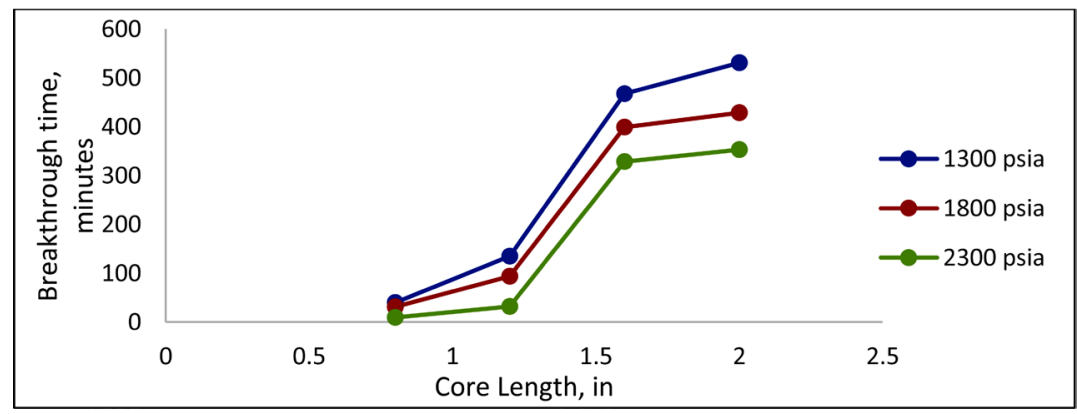

Figure 8. BT of samples at their core lengths before acid treatment. 
sample S1. Also as can be seen from the Figure 8, BT increases with increasing core length. This is because longer core length provides more surface area and more pore volume to accommodate more oil.

\subsubsection{BT at Different Injection Pressures before Acid Treatment}

From Figure 9, injection pressures had great influence on BT, with lower injection pressures having higher BT. Sample S4 had the longest BT because of its longer core lengths at injection pressure of 1300 psia followed by sample S3. From the figure, it can be observed that BT decreases with increasing injection pressure.

\subsubsection{BT at Different HCL Concentration after Acid Treatment}

From Figure 10, after acid treatment, the cores show lower BT even at very low injection pressures. At 350 psia, the BT for sample S1 at 15\% HCL concentration was 2 minutes. This is much lower than the BT for 1300 psia for the same core sample which was 40 minutes before acid treatment. From the figure, the lowest BT is gotten from $20 \%$ HCL concentration, while the highest BT is gotten from $5 \%$ HCL concentration for all core samples. Thus, acid reduces the strength of the cores and makes it susceptible to breakage even at lower pressures; this is the reason for the dissolution and fracture by the acid during acidizing treatment on cores.

\subsection{Average Penetration Rate (APR)}

The average time of penetration for the core samples before and after the acid treatment are given below.

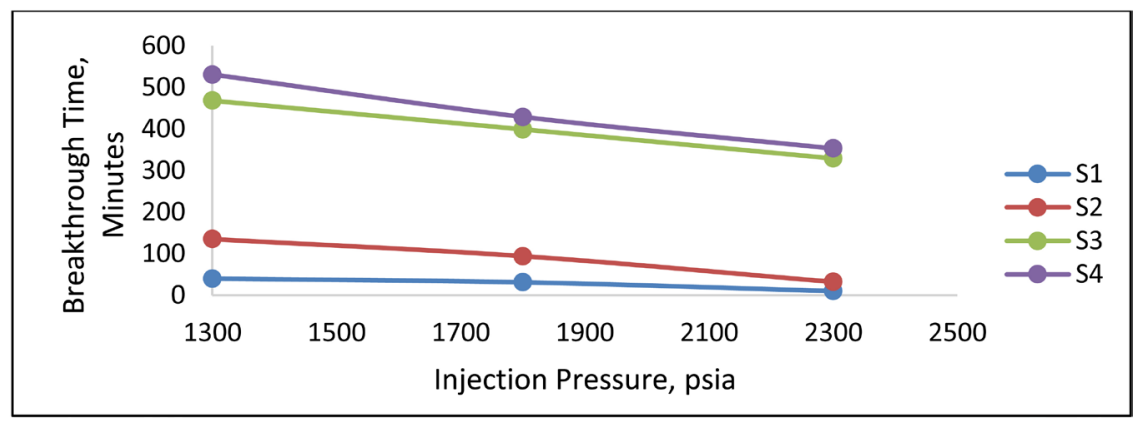

Figure 9. BT at different injection pressures before acid treatment.

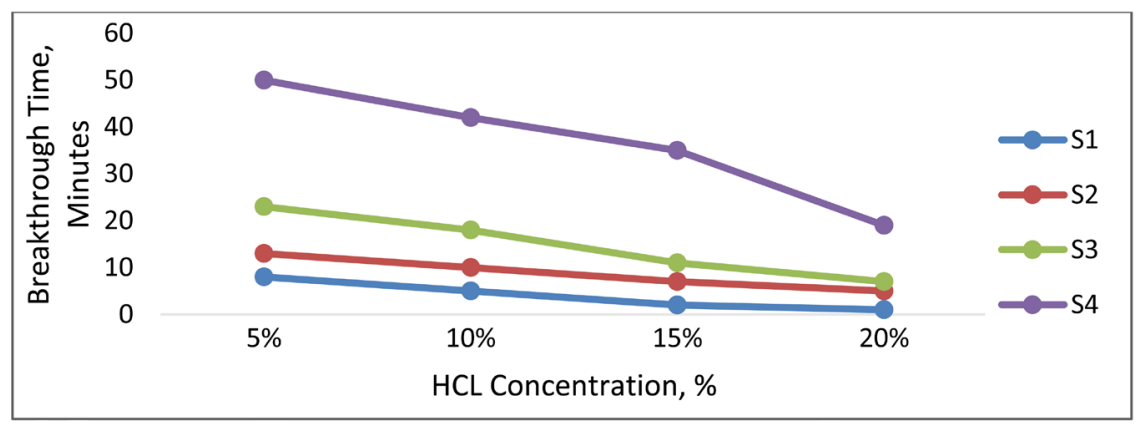

Figure 10. BT at different HCL concentrations after acid treatment. 


\subsubsection{APR before Acid Treatment}

From Table 2 and Figure 11, the APRs before acid treatment are $247.66 \mathrm{~min} / \mathrm{in}$, $198.91 \mathrm{~min} / \mathrm{in}$ and $139.95 \mathrm{~min} / \mathrm{in}$ for $1300 \mathrm{psia}, 1800$ psia and 2300 psia respectively. The APR decreases with increase in injection pressure. From Figure 11, the highest APR was at 1300 psia which with $247.66 \mathrm{~min} / \mathrm{in}$. Following the equation of the trend line, the calculated APR for 350 psia would be $312.21 \mathrm{~min} / \mathrm{in}$. Thus the lower the injection pressure, the higher the APR. Also from Table 3, the APR for various samples are given below: Sample S1 had $67.5 \mathrm{~min} / \mathrm{in}, \mathrm{S} 2 \mathrm{had}$ $108.75 \mathrm{~min} / \mathrm{in}$., S3 had $332.22 \mathrm{~min} / \mathrm{in}$. and S4 had $273.54 \mathrm{~min} / \mathrm{in}$. The highest PR was observed from sample S3 because of its higher permeability.

\subsubsection{APR after Acid Treatment}

Figure 12 depicts APR as a function of HCL concentration after acid treatment at 350 psia. From Figure 12, the APRs are $21.67 \mathrm{mi} / \mathrm{in} ., 16.56 \mathrm{~min} / \mathrm{in} ., 11.2$ $\mathrm{min} / \mathrm{in}$. and $6.61 \mathrm{~min} / \mathrm{in}$ for HCL concentration of $5 \%, 10 \%, 15 \%$ and $20 \%$ respectively. It can be observed from the figure that there is a linear decline of APR with acid concentration. The higher the acid concentration, the lower the APR into the core. From Figure 11, the calculated APR for 350 psia injection pressure before acid treatment was calculated to be $312.21 \mathrm{~min} / \mathrm{in}$., but after acid treatment, the penetration rate for each of the HCL concentration became drastically smaller than the value of $312.21 \mathrm{~min} / \mathrm{in}$. The profound reduction in penetration

Table 2. APR for injection pressures before acid treatment.

\begin{tabular}{cc}
\hline Injection Pressure, psia & Average Penetration rate min/in. \\
\hline 1300 & 247.66 \\
1800 & 198.91 \\
2300 & 139.95 \\
\hline
\end{tabular}

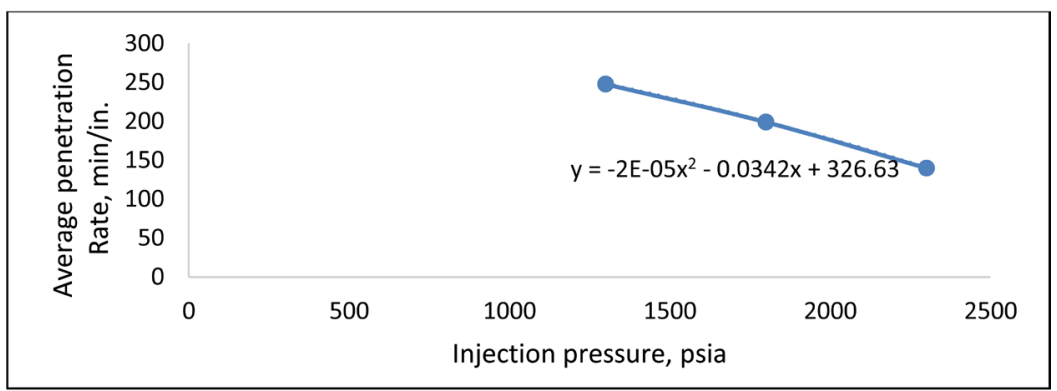

Figure 11. APR and the injection pressure before acid treatment.

Table 3. APR for various samples before acid treatment.

\begin{tabular}{cc}
\hline Sample & Average Penetration rate, $\mathrm{min} / \mathrm{in}$ \\
\hline S1 & 67.5 \\
S2 & 108.75 \\
S3 & 332.22 \\
S4 & 273.54 \\
\hline
\end{tabular}




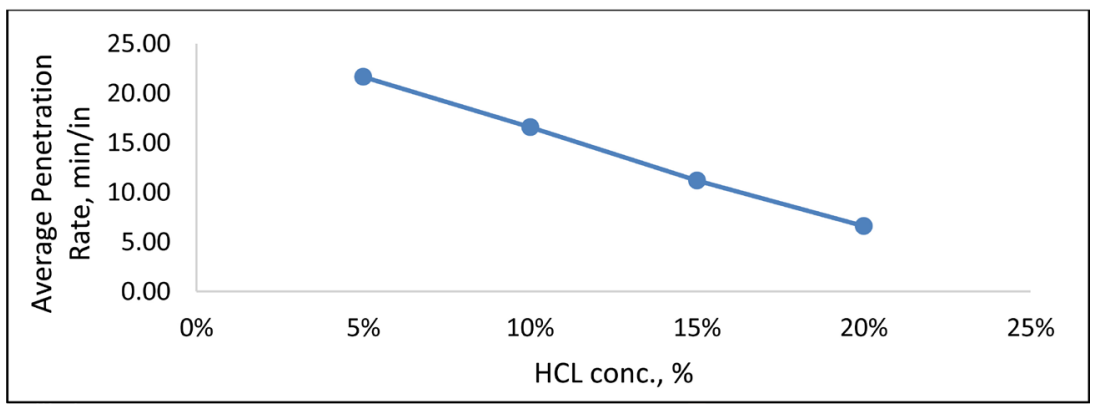

Figure 12. APR vs. HCL concentration after acid treatment at injection pressure of 350 psia.

Table 4. APR for all core samples after acid treatment.

\begin{tabular}{cc}
\hline Sample & APR, min/in. \\
\hline S1 & 10 \\
S2 & 10.94 \\
S3 & 12.29 \\
S4 & 22.81 \\
\hline
\end{tabular}

rate was as a result of the acid treatment which results in higher permeability of the cores. Also from Table 4, acid treatment greatly reduced the APR for each of the core samples utilized for the experiment even though the injection pressure was as low as 350 psia.

\section{Conclusions and Recommendations}

\subsection{Conclusions}

The research conducted has shown that matrix acidizing using HCL acids can be applied to the Niger Delta shale formation as a means of tapping the unconventional shale reserves in Niger Delta. From the research, these conclusions are drawn:

1) Increase in injection pressure leads to increase in oil recovery and decrease in penetration rate. However, very high injection pressure may lead to very early breakthrough.

2) The higher the acid concentration used in the acidizing, the higher the oil recovery. However, optimal acid concentrations must be chosen with regards to operational economics and recovery index.

3) Acid treatment on cores widened natural fractures creating higher permeabilities which favours the recovery of more oil.

4) After acid treatment, the BT was lowered from 531 minutes for 1300 psia injection pressure to 2 minutes at 15\% HCL concentration even though the injection pressure was lowered to 350 psia.

5) Matrix acidizing using HCL results in favourable oil recovery even at low flooding pressures when compared to flooding without treatment at the same pressures. 
6) Acid matrix stimulation enhances productivity of shale formation.

\subsection{Recommendations}

Matrix acidizing using HCL acids should be applied in the Niger Delta shale formation as a means of tapping the unconventional shale reserves in the Niger Delta. The government should focus more in the development of unconventional shale reserves as the light petroleum reserves are rapidly exhausting. Matrix acidizing among other innovative practice is a solution to the complexities encountered in shale reservoir geology.

\section{Acknowledgements}

The authors sincerely appreciate the necessary assistance provided by Dr Chume Onyemere of Jackron Engineering Ltd. in ensuring that this research is realized by providing the needed samples and also rendering necessary advice when required.

\section{Conflicts of Interest}

The authors declare no conflicts of interest regarding the publication of this paper.

\section{References}

[1] Fontaine, J., Johnson, N. and Schoen, D. (2008) Design, Execution, and Evaluation of a Typical Marcellus Shale Slickwater Stimulation: A Case History. SPE Eastern Regionall AAPG Eastern Section Joint Meeting, Pittsburgh, 11-15 October 2008, Paper SPE 117772-MS. https://doi.org/10.2118/117772-MS

[2] Morsy, M., Sheng, J.J., Hetherington, C.J., Mohamed, Y.S. and Ezewu, R.O. (2013) Impact of Matrix Acidizing on Shale Formations. SPE Nigeria Annual International Conference and Exhibition, Lagos, 5-7 August 2013, Paper SPE 167568. https://doi.org/10.2118/167568-MS

[3] Davies, D.R., Faber, R., Nitters, G. and Ruessink, B.H. (1992) A Novel Procedure to Increase Well Response to Matrix Acidizing Treatments. 2nd SPE Latin American Petroleum Engineering Conference, Caracas, 8-11 March 1992, Paper SPE 23621.

[4] Okologume, C.W. and Umeleuma, M.B. (2015) Evaluation of a Systematic Approach to Matrix Acidizing on an Oil Producing Well. International Research Journal of Engineering and Technology, 4, 2321-7308.

[5] Bale, A., Smith, M.B. and Henry Klein, H.H. (2010) Stimulation of Carbonates Combining Acid Fracturing with Proppant (CAPF): A Revolutionary Approach for Enhancement of Final Fracture Conductivity and Effective Fracture Half-Length. SPE Annual Technical Conference and Exhibition, Florence, 19-22 September 2010, Paper SPE-134307-MS. https://doi.org/10.2118/134307-MS

[6] El Shaari, N., Minner, W.A. and LaFollette, R.F. (2011) Is There a "Silver Bullet Technique" to Stimulating California. SPE Western North American Region Meeting, Anchorage, 7-11 May 2011, SPE-144526-MS. https://doi.org/10.2118/144526-MS

[7] Sheng, J., Morsy, S., Gomaa, A. and Soliman, M.Y. (2014) Matrix Acidizing Characteristics in Shale Formations. Journal of Petroleum and Environmental Biotech- 
nology, 5, 194.

[8] Farley, J.T., Miller, B.M. and Schoettle, R.S. (1970) Design Criteria for Matrix Stimulation with Hydrofluoric-Hydrochloric Acid Systems. JPT, 22, 433-440, Paper SPE 2621-PA. https://doi.org/10.2118/2621-PA

[9] Patton, B.J., Pitts, F., Goeres, T. and Hertfelder, G. (2003) Matrix Acidizing Case Studies for the Point Arguello Field. SPE Western Regionall AAPG Pacific Section Joint Meeting, Long Beach, 19-24 May 2003, Paper SPE-83490-MS. https://doi.org/10.2118/83490-MS

[10] Paccoloni, G. and Tambini, M. (1983) Advances in Matrix Stimulation Technology. Journal of Petroleum Technology, 45, Paper SPE 20623.

[11] Montgomery, C.T., Jan, Y.-M. and Niemeyer, B.L. (1995) Development of Matrix Acidizing Stimulation Treatment Evaluation and Recording System. SPE Production \& Facilities, 10, Paper SPE 26579-PA. https://doi.org/10.2118/26579-PA

[12] Ricardo, A., Kern, S., Leandro, F. and Leonard, K. (2007) Effective Matrix Acidizing in High Temperature Environments. SPE Annual Technical Conference and Exhibition, Anaheim, 11-14 November 2007, Paper SPE 109818.

[13] Krueger, R.F. (1986) An Overview of Formation Damage and Well Productivity in Oil Field Operations. Journal of Petroleum Technology, 38, Paper SPE 10029. https://doi.org/10.2118/10029-PA

[14] Krueger, R.F. (1988) An Overview of Formation Damage and Well Productivity in Oilfield Operations: An Update. SPE California Regional Meeting, Long Beach, 23-25 March 1988, Paper SPE 17459. https://doi.org/10.2118/17459-MS

[15] Williams, B.B. and Whitely, M.E. (1971) Hydrofluoric Acid Reaction with Porous Sandstone. Society of Petroleum Engineers Journal, 11, Paper SPE-3112-PA. https://doi.org/10.2118/3112-PA

[16] Thomas, R.L. and Crowe, C.W. (1981) Matrix Treatment Employs New Acid System for Stimulation and Control of Fines Migration in Sandstone Formations. Journal of Petroleum Technology, 33, Paper SPE 7566. https://doi.org/10.2118/7566-PA

[17] McCabe, W.D., Hampton, T.J. and Querin, M.E. (1996) Acid Stimulation Increases Production in 31S C/D Shale Reservoirs, Monterey Formation, Elk Hills Field, California. SPE Western Regional Meeting, Anchorage, 22-24 May 1996, SPE 35745. https://doi.org/10.2118/35745-MS

[18] Ekweozor, C.M. and Unomah, G.I. (1990) First Discovery of Oil Shale in the Benue Trough, Nigeria. Fuel, 69, 502-508. https://doi.org/10.1016/0016-2361(90)90322-H

[19] U.S. Geological Survey (USGS) (1999) Niger Delta Petroleum System. https://pubs.usgs.gov/of/1999/ofr-99-0050/OF99-50H/ChapterA.html

[20] Sonibare, O.O., Jacob, D.E., Ward, C.R. and Foley, S.F. (2011) Mineral and Trace Element Composition of the Lokpanta Oil Shales in the Lower Benue Trough, Nigeria. Fuel, 90, 2843-2849. https://doi.org/10.1016/j.fuel.2011.04.037

[21] Akinlo, A.E. (2012) How Important Is Oil in Nigeria's Economic Growth? Journal of Sustainable Development, 5, 165-179. https://doi.org/10.5539/jsd.v5n4p165

[22] Khalil, R.E., Mansour, A. and Gamdi, T. (2017) An Experimental Study of Acid Matrix Treatment Performance on Shale Core Samples. SPE Liquids-Rich Basins Conference-North America, Midland, 13-14 September 2017, Paper SPE-187478-MS. https://doi.org/10.2118/187478-MS 


\section{Nomenclature}

$\mathrm{XRD}-\mathrm{X}$ ray diffraction

$\mathrm{XR}-\mathrm{X}$ ray

HCL-Hydrocloric acid

$\mathrm{NaCl}$-Sodium chloride

Nanoperm-Nanodarcy permeameter

$\mathrm{Ppm}-$ parts per million

BT-Breakthrough time

APR-Average Penetration Rate

PR-Penetration Rate

Psia-Pounds per square inch absolute

Vs.-Versus 